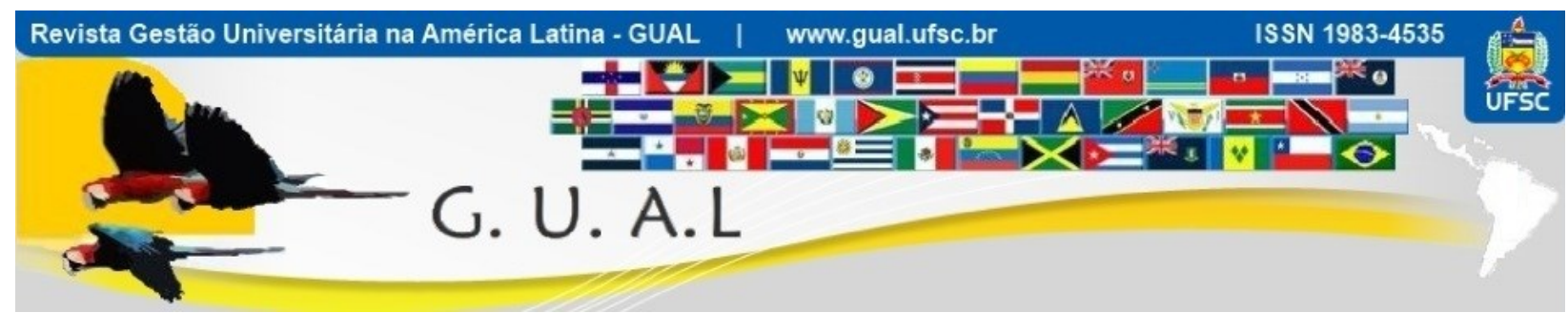

DOI: https://doi.org/10.5007/1983-4535.2021.e79353

\title{
PROGRAMA DE ASSISTÊNCIA ESTUDANTIL: IMPACTOS DA BOLSA PERMANÊNCIA PARA ESTUDANTES DA MODALIDADE EAD
}

\section{STUDENT ASSISTANCE PROGRAM: IMPACTS OF THE PERMANENCE SCHOLARSHIP FOR STUDENTS IN EAD MODALITY}

$\begin{array}{r}\text { Danielle França Ribeiro, Graduada } \\ \text { https://orcid.org/0000-0001-5979-5969 } \\ \text { daniellefr96@gmail.com }\end{array}$
Universidade Federal Rural do Semi-Árido | Mestrado Profissional em Administração Pública
Mossoró | Rio Grande do Norte | Brasil
Napiê Galvê Araújo Silva, Doutor
https://orcid.org/0000-0002-7966-3311
pie@ufersa.edu.br
Universidade Federal Rural do Semi-Árido | Mestrado Profissional em Administração Pública
Mossoró | Rio Grande do Norte | Brasil

Recebido em $03 /$ fevereiro/2021

Aprovado em 12/julho/2021

Publicado em 01/setembro/2021

Sistema de Avaliação: Double Blind Review 


\title{
RESUMO
}

A democratização do ensino superior ainda encontra muitas barreiras para sua efetivação. Um dos mecanismos que podem contribuir para uma verdadeira inclusão de alunos em situação de vulnerabilidade socioeconômica é o Apoio à Permanência estudantil, inclusive o Programa de Bolsa Permanência. Contudo, não existem documentos direcionados para o apoio de alunos da modalidade a distância, apesar disso, algumas universidades dispõem de bolsas permanências para estes alunos. Este estudo tem como objetivo analisar, na percepção dos discentes beneficiados, a influência da bolsa permanência para a continuidade e bom desempenho no curso a distância. Trata-se de uma pesquisa qualitativa delimitada aos alunos de uma universidade federal do semiárido potiguar, cursistas de licenciaturas da modalidade a distância. Como método de coleta de dados utilizou-se a aplicação de questionário online. A pesquisa coletou dados de 15 beneficiados pelo programa de bolsa permanência. Por meio da análise de dados, observa-se que a bolsa permanência contribui para a continuidade e aumento do comprometimento com o curso, além de permitir que o aluno entre em contato com atividades extracurriculares. Nota-se, também, que o valor do benefício é distribuído de variadas formas pelos alunos, tanto com itens diretamente relacionados ao curso, como por itens pessoais e domiciliares.

Palavras-chave: Assistência Estudantil. Ensino Superior. Educação a Distância.

\begin{abstract}
The democratization of higher education still faces many barriers to its effectiveness. One of the mechanisms that can contribute to a real inclusion of students in a situation of socioeconomic vulnerability is the Support for Student Permanence, including the Bolsa Permanência Program. However, there are no documents aimed at supporting distance learning students, despite that, some universities have permanent scholarships for these students. This study aims to analyze, in the perception of the benefited students, the influence of the permanent scholarship for continuity and good performance in the distance course. This is a qualitative research limited to students from a federal university in the semi-arid region of Rio Grande do Norte, undergraduate students in distance learning. As a method of data collection, an online questionnaire was used. The survey collected data from 15 beneficiaries of the permanence scholarship program. Through data analysis, it is observed that the scholarship contributes to the continuity and increased commitment to the course, in addition to allowing the student to get in touch with extracurricular activities. It is also noted that the value of the benefit is distributed in various ways by students, both with items directly related to the course, as well as personal and home items.
\end{abstract}

Keywords: Student Assistance. Higher Education. Distance Education. 


\section{INTRODUÇÃO}

Um dos desafios presentes na contemporaneidade é dar condições de acesso à educação, direito humano universal, para a pluralidade de sujeitos com diversidades sociais, econômicas e culturais. Dessa forma, gradativamente verifica-se o aumento de movimentos e ações que visam expandir o acesso, qualidade e continuidade do ensino.

O indivíduo, visto como sujeito social, torna-se modificador do seu ambiente por meio dos conhecimentos adquiridos e das ações transformadoras que pratica em decorrência da educação. A relevância da educação é constatada no artigo $205^{\circ}$ da Constituição Federal Brasileira de 1988, que a compreende como direito de todos e dever do Estado e da família, visando o pleno desenvolvimento do indivíduo tanto para exercício da cidadania como qualificação para o trabalho (BRASIL, 1998).

Consistindo em um direto, a educação deve ser assegurada a todos os cidadãos de forma digna, igualitária e equânime. O Plano Nacional de Educação (PNE) estabelece como algumas de suas diretrizes, em concordância com o disposto na Constituição Federal, a superação das desigualdades educacionais; promoção humanística, científica, cultural e tecnológica do País; promoção dos princípios do respeito aos direitos humanos, à diversidade e a sustentabilidade socioambiental (BRASIL, 2014).

À vista disso, a educação é considerada como elemento primordial para o desenvolvimento dos indivíduos e nações. O desenvolvimento, neste sentido, é entendido sobre a perspectiva de Amartya Sen, que pensa o desenvolvimento de forma abrangente, atrelando este com a expansão de liberdades. Além do aspecto da renda, o desenvolvimento depende de outras disposições sociais, como acesso à educação, saúde, direitos civis (SEN, 1999).

A democratização do ensino superior, por meio de políticas de acesso, representou a possibilidade de ingresso no terceiro grau para muitos grupos que, a priori, estavam marginalizados por questões econômicas, sociais e históricas. O acesso à educação, especialmente para estes grupos, representou o instrumento para o exercício da autonomia e da conquista de outras liberdades, como diminuição da vulnerabilidade socioeconômica.

Uma das modalidades de ensino que contribuiu para a democratização do ensino superior foi a educação a distância $(\mathrm{EaD})$. Por intermédio das tecnologias de informação e comunicação (TICs), as instituições conseguem atender pessoas de diversas localidades e que 
possuem indisponibilidade de acesso ou de tempo para ir à sala de aula tradicional (ALVES, 2011).

A expansão do acesso à universidade, em especial para grupos anteriormente negligenciados, acarreta a necessidade de um novo olhar para a equidade na educação. Esta conjuntura aumenta a demanda por políticas de assistência estudantil que proporcionem aos discentes, especialmente aqueles em situação de vulnerabilidade socioeconômica, condições de permanecer e concluir o curso. A expansão das vagas, sem o devido suporte aos alunos, pode ser considerado como um tipo de inclusão injusta, isto é, formas desfavoráveis de inclusão e condições adversas de participação (SEN; KLIKSBERG, 2010).

Dentre as ações assistenciais, destaca-se o Programa Nacional de Assistência Estudantil (PNAES) que tem a finalidade de ampliar as condições de permanência dos jovens de baixa renda na educação superior pública federal, e, para tanto, objetiva democratizar as condições de permanência; minimizar os efeitos das desigualdades sociais e regionais na permanência e conclusão do curso; reduzir as taxas de repetência e evasão; além de contribuir para promoção da inclusão social pela educação (BRASIL, 2010).

O PNAES é direcionado para os discentes das graduações presencias, contudo, progressivamente, observa-se a expansão da modalidade de ensino a distância. Diante disso, cresce a importância de pensar ações que venham a assistir os alunos em vulnerabilidade socioeconômico dessa realidade.

À vista disso, o presente estudo busca analisar, na percepção dos discentes beneficiados, a influência da bolsa permanência para a continuidade e bom desempenho no curso de graduação a distância. A pesquisa possui como recorte os alunos de uma universidade pública federal do semiárido potiguar vinculados a cursos da modalidade a distância do programa Universidade Aberta do Brasil (UAB).

Para cumprir o objetivo exposto, serão identificados os fatores que oportunizam e dificultam a permanência e o desempenho dos discentes nos cursos de graduação a distância; verificada a relação entre o programa de bolsa permanência e indicadores de desempenho acadêmico; e verificado se a bolsa permanência incentivou o contato dos discentes com atividades complementares a sua formação acadêmica. 


\section{EDUCAÇÃO SUPERIOR NO BRASIL}

Dentro da política educacional é constante o debate sobre a democratização do ensino superior, especialmente relacionado a maior ampliação de acesso e equidade. Neste ínterim, ocorrem as criações de novas instituições de ensino superior, utilização das TICs como intermediadores do ensino, além da elaboração e ampliação de políticas de inclusão social e ações afirmativas (NEVES; RAIZER; FACHINETTO, 2007).

Apresentando-se como uma das tendências para o ensino superior, a modalidade de ensino a distância atende aos propósitos de viabilizar acesso à educação de qualidade menos desigual para grupos diversos. Isso ocorre, pois devido a utilização da TICs e internet, barreiras com relação a limitação de tempo e lugar podem ser transpostas (FERRUGINI et al., 2013).

Contudo, outros impasses também afetam a inclusão e permanência do discente no ensino superior. A autora Costa (2010) lista, como intrínsecas à permanência dos discentes, questões de ordem pedagógica, psicológica e econômica, que carecem de outros mecanismos para serem superadas.

As questões mencionadas influenciam no processo de abandono dos estudos. A educação superior brasileira possui um alto índice de evasão, uma das principais razões para este cenário é a falta de condições financeiras dos discentes em prosseguir com os estudos. Este processo de saída prematura da universidade representa desperdícios sociais, acadêmicos e econômicos (Lobo et al., 2007).

Em complemento a Costa (2010) e Lobo et al. (2007), Simielli (2015) elenca fatores internos e externos à instituição de ensino que impactam no desempenho escolar. Para a referida autora, são influentes as condições familiares e comunidade no qual o aluno está inserido; etnia, nível socioeconômico, gênero e saúde. Nesse sentido, aspectos relacionados à escolaridade dos pais, apoio familiar para a educação, nível socioeconômico dos pares e parcerias entre instituição de ensino e comunidade, tornam-se elementos de grande relevância para o desempenho escolar.

As autoras citadas convergem para o entendimento de que a vulnerabilidade socioeconômica ocasiona impactos negativos no processo de democratização do ensino e alcance de uma educação equânime. A concepção de vulnerabilidade socioeconômica está relacionada não apenas à ausência ou precariedade no acesso à renda, mas, também às privações de acesso a outros bens e serviços públicos (CARMO; GUIZARDI, 2018). As 
privações dessas liberdades caracterizam-se como um processo de "mão dupla", visto que a precariedade de acesso a renda provoca privações de outros tipos de liberdades (como, por exemplo, saúde e educação), ao passo que, a privação de acesso a essas liberdades reforçam a limitação de renda (SEN, 1999).

De acordo com Sen e Kliksberg (2001), um sistema seria justo quando garantisse a igualdade de oportunidades para todos. Para Sen (1999), os indivíduos devem ter a liberdade de alcançar a qualidade e modo de vida que gostariam de ter. As liberdades econômicas, políticas, civis e sociais permitem que as pessoas "levem a vida" como valorizam. Neste entendimento, o acesso ao ensino superior além da exigência econômica, também representa um indicador do desenvolvimento da democracia e da justiça social (COSTA, 2010).

O ensino superior, para alunos em condição de vulnerabilidade socioeconômico, é visto como um mecanismo para mobilidade social, de melhoria de condições individuais e familiar (BROCCO, 2017). Para os discentes, a educação superior é o meio para galgar uma melhor colocação no mercado de trabalho, com remuneração mais satisfatória e reconhecimento social.

A expansão do ensino superior é primordial para a democratização da educação e seu consequente impacto social. Neste sentido, os cursos superiores a distância tem se destacado como forma de ampliar o acesso ao ensino. A modalidade de educação a distância tem crescido no Brasil, mobilizando grande contingentes de recursos governamentais e de iniciativa privada (GUIMARÃES, 2017). Conforme dados oriundos do Instituto Nacional de Estudos e Pesquisa Educacionais Anísio Teixeira (INEP), no período de 2013 a 2014 houve aumento de 41,2\% no ingresso de alunos na modalidade a distância, enquanto, no mesmo intervalo de tempo, a educação presencial cresceu 7\% (BRASIL, 2015).

$\mathrm{Na}$ EaD destaca-se o sistema UAB, instituído pelo Decreto $\mathrm{n}^{0} 5.800$, de 8 de junho de 2006, com a finalidade de interiozar e democratizar a educação superior no Brasil, priorizando a capacitação de professoras da educação básica, mas também atendendo à comunidade geral. Por intermédio dos polos de apoio presencial, normalmente localizados nas cidades do interior, as universidades se aproximam dos mais diversos alunos. Para Borges (2015), o Sistema UAB tem sido motor de impulso que tem proporcionado o contato dos municípios mais interiorizados com a universidade e vice-versa.

Mesmo diante do cenário de gradativa ampliação de vagas, os gestores da $\mathrm{EaD}$ enfrentam dificuldades com relação a permanência dos discentes. Sobre o assunto, Guimarães 
(2017) aponta sobre a necessidade de o gestor ter conhecimento sobre as causas que impactam na permanência e evasão dos alunos na EaD. Sendo possível, dessa forma, propor estratégias direcionadas ao contexto real que diminuam os índices de evasão dos cursos e desenvolvam o estudante pessoal e profissionalmente.

Diante do exposto, no contexto da educação superior é necessário a elaboração e execução de mecanismos que garantam não apenas o acesso ao terceiro grau, mas, também a permanência dos discentes, por meio de suportes para os alunos em condição de vulnerabilidade socioeconômica, reduzindo os efeitos das desigualdades e exclusão social.

\section{POLÍTICA DE ASSISTÊNCIA ESTUDANTIL}

As fragilidades socioeconômicas dos alunos e a influência delas no acesso e permanência dos discentes já haviam sido observadas desde meados do século XX. A Constituição Federal de 1934 , em seu artigo $157^{\circ}$, previa a doação de fundos a estudantes necessitados, como assistência alimentar, disponibilização de bolsa de estudo e fornecimento de material escolar (BETZEK, 2015). Entretanto, a concretização dessas ações governamentais viera ocorrer apenas após reivindicações populares e pressão da classe estudantil. A alocação de recursos e a criação do Programa Nacional de Assistência Estudantil (PNAES) em 2010 demostraram a preocupação governamental com expansão e democratização do acesso ao ensino superior (FONAPRACE, 2019).

A promoção da política de assistência social no Brasil é pertinente pois o suporte promovido aos discentes contribui para a democratização do ensino superior e se traduz em ações de compromisso ao atendimento de demandas sociais. De acordo com Alves (2002, p.3), "a busca da redução das desigualdades socioeconômicas faz parte do processo de democratização da universidade e da própria sociedade brasileira".

A pesquisa realizada no ano de 2018 pelo Fórum Nacional de Pró-Reitores de Assuntos Estudantis (FONAPRACE), que coletou de 1.200.300 (um milhão, duzentos mil e trezentos) estudantes de graduação das Instituições Federais de Ensino Superior (IFES) dados sobre o perfil socioeconômico, encontrou o percentual de $70,2 \%$ do universo pesquisado com faixa de renda familiar per capita de até 1,5 salários mínimos (FONAPRACE, 2019).

Conforme Decreto $\mathrm{N}^{\mathrm{o}} 7.234$, de 19 de julho de 2010, o público alvo das políticas de assistência estudantil são alunos oriundos da rede pública de educação básica ou com renda familiar per capita de até 1,5 salário mínimo (BRASIL, 2010). Observa-se, com base no 
relatório da FONAPRACE, que três a cada quatro discentes atendem a faixa de renda proposta pelo referido Decreto.

Ainda segundo a pesquisa supracitada da FONAPRACE, os serviços mais demandados pelos discentes dentre aqueles propostos pelo PNAES são alimentação $(17,3 \%)$, bolsas $(9,4 \%)$, transporte $(8,2 \%)$ e moradia $(7,5 \%)$. A pesquisa também levantou que entre as principais razões para o abandono do curso estão as dificuldades financeiras (32,8\%), nível de exigência acadêmico $(29,7 \%)$ e dificuldades para conciliar os estudos e o trabalho $(23,6 \%)$ (FONAPRACE, 2019).

Entre as ações implementadas através do PNAES, ressalta-se o Programa de Bolsa Permanência. Instituído pela Portaria $n^{\circ} 389$, de 9 de maio de 2013, é um auxílio financeiro destinado ao público em vulnerabilidade socioeconômica que visa minimizar as desigualdades e contribuir para permanência e conclusão do curso (BRASIL, 2013).

Conforme Art. $3^{\circ}$ do Decreto $n^{\circ} 7234 / 2010$, o Programa de Bolsa Permanência deve ser implementado de forma articulada com atividades de ensino, pesquisa e extensão (BRASIL, 2010). A assistência estudantil quando relacionada as atividades mencionadas promove um efeito importante no desempenho acadêmico, nos índices de conclusão e na diminuição da evasão (SALES, 2019).

De fato, o Censo da Educação Superior de 2016 indica que os maiores índices de conclusão estão relacionados a participação dos discentes em atividades do tripé universitário (ensino, pesquisa e extensão) e a existência de programas de assistência estudantil (INEP, 2017). O auxílio financeiro contribui para o desenvolvimento acadêmico do discente ao passo que pode contribuir na aquisição de livros, equipamentos, oportunizar a participação de eventos acadêmicos e culturais (ALVES, 2002).

\section{PROCEDIMENTO METODOLÓGICO}

O presente estudo representa o olhar dos bolsistas sobre as dificuldades para permanecer no curso a distância e a influência da bolsa permanência para continuidade e conclusão do mesmo. Dessa forma, se qualifica como qualitativo visto que busca as opiniões e perspectivas dos sujeitos abrangendo o contexto onde estão inseridas (YIN, 2016). Por sua natureza ser prática, buscando resolver questões concretas, o estudo também classifica-se como aplicado. Ademais, mediante a análise profunda de uma realidade específica que pode 
basear a compreensão de outra realidade em condições semelhantes, define-se esta pesquisa como um estudo de caso.

A pesquisa está delimitada aos alunos de uma universidade federal do semiárido potiguar, cursistas de licenciaturas da modalidade a distância e vinculados à bolsa permanência.

Optou-se por esses sujeitos devido ao porte e importância que a instituição possui na região. Ademais, pela trajetória que a mesma possui na EaD, desde 2011 ofertando cursos de graduação, aperfeiçoamento e especialização para formação inicial e continuada dos discentes. Atendendo alunos distribuídos em quase 90 cidades nos estados do Rio Grande do Norte, Ceará e Paraíba.

Em virtude do número pequeno de beneficiados do programa bolsa permanência, definiu-se que a pesquisa tentaria alcançar todos os sujeitos, isto é, os 26 discentes. Desse quantitativo, 15 alunos participaram da pesquisa dentro do período proposto. Para a identificação dos beneficiários do programa, foi requerida à coordenação da instituição autorização e disponibilização da listagem de discentes beneficiados com seus respectivos contatos

A coleta de dados ocorreu por meio de formulário eletrônico enviado aos sujeitos via Ambiente Virtual de Aprendizagem (AVA) e aplicativo de mensagem. O formulário foi constituído por 21 perguntas entre fechadas e abertas, que compreendiam os aspectos de perfil discente, perfil socioeconômico, auto avaliação acadêmica, aspectos da bolsa permanência. As respostas eram anônimas. A coleta de dados ocorreu em dezembro de 2019.

A análise de dados ocorreu por meio da interpretação dos dados primários mediante o método de Estatística Descritiva, com o suporte do programa Excel. Para tanto, foi realizado a tabulação marginal, que consiste na contagem das frequências das categorias de cada conjunto (GIL, 2008).

\section{DISCUSSÃO DOS RESULTADOS}

\subsection{PROGRAMA DE BOLSA PERMANÊNCIA NA UNIVERSIDADE ESTUDADA}

Em atendimento ao Decreto $\mathrm{N}^{0} 7.234 / 2010$, a universidade estudada instituiu o Regulamento do Programa Institucional de Permanência no ano de 2010. O documento define os parâmetros para disponibilização e continuidade dos pagamentos e auxílios no âmbito da instituição. Possui como objetivo ampliar as condições de permanência dos alunos em 
situação de vulnerabilidade socioeconômica de cursos de graduação presencial. Logo, não é direcionado para os alunos da modalidade a distância, apesar de, servir de referência para o programa de apoio estudantil dos cursos à distância, visto que esses não possuem regulamento próprio sobre assistência estudantil.

No Regulamento do Programa Institucional de Permanência, o auxílio financeiro é condicionado à alguma atividade de ensino, pesquisa, extensão ou cultura, conforme estabelecido no Art. $3^{\circ}$ do Decreto $n^{\circ} 7234 / 2010$ (BRASIL, 2010). Visando apoiar a formação do discente ao passo que proporciona condições mínimas para sua manutenção no curso.

Para continuidade no programa de bolsa permanência, o regulamento da instituição estabelece em seu artigo $4^{\circ}$ que o aluno perderá automaticamente o benefício caso reprove mais de duas vezes durante a vigência da bolsa, ou ainda, seja reprovado por falta, assim como, alcance Índice de Rendimento Acadêmico (IRA) inferior a 5,0.

Neste sentido, observa-se que o regulamento de assistência estudantil da universidade em análise estabelece diretrizes que relaciona o benefício a uma atividade que agregue ao perfil profissional ou pessoal do aluno, além de, estabelecer desempenhos mínimos aceitáveis para a continuidade do mesmo, o que pode vir a estimular uma melhor performance acadêmica. A melhoria do rendimento acadêmico pode ocorrer, também, devido a possibilidade de o aluno adquirir livros, equipamentos, oportunidades de participação de eventos acadêmicos e culturais, contribuindo para que o discente desenvolva sua plenitude acadêmica, situação mencionada por Alves (2002).

\subsection{ANÁLISE DO PERFIL DOS DISCENTES BENEFICIADOS}

Considerando a importância da descrição dos sujeitos pesquisados, foi levantado o perfil dos discentes beneficiados com o programa de bolsa permanência na universidade pesquisada. Para tanto, houve perguntas sobre sexo, idade, etnia, quantidade de membros no núcleo familiar e renda mensal total da família. Ademais, também houve questões sobre curso, polo presencial que estão vinculados e município em que residem.

Dentre os sujeitos, oito são do sexo feminino e sete são do sexo masculino. Identificase, também, que as idades variam de 21 a 35 anos, havendo uma concentração maior de 21 a 25 anos. Além disso, 11 sujeitos se auto declararam pardos e quatro brancos, não havendo presença de outras etnias. Com relação a quantidade de membros que compõe o núcleo 
familiar, verificou-se uma variação de 1 a 11 pessoas, sendo mais expressiva a quantidade de três pessoas no núcleo.

Sobre a renda mensal da família, $60 \%$, isto é, nove discentes tem a renda familiar de um salário mínimo do ano base 2019 (R \$ 998,00), sendo a média das rendas mensais de R\$ 954,07 e a renda familiar mais alta levantada de R\$1500,00. Com base nos dados, pode inferir-se que a renda per capita varia entre $R \$ 89,00$ e $R \$ 446,67$, sendo $R \$ 257,58$ a média das rendas per capitas. Os dados sobre renda obtidos na pesquisa condizem com as faixas salarias previstas no Decreto $\mathrm{N}^{0} 7.234 / 2010$ (BRASIL, 2010)

Com relação ao curso, observou-se que seis sujeitos são do curso de Licenciatura em Computação; cinco são do curso de Licenciatura em Física; três são discentes da Licenciatura em Matemática; e apenas um respondente é do curso de Licenciatura em Química. No que se refere ao polo de apoio presencial, houve grande representatividade do polo de Angicos/RN com $46,7 \%$, isto é, sete discentes.

Ainda com relação ao perfil dos sujeitos pesquisados, constatou-se que todos os alunos beneficiados que responderam a pesquisa residem em cidades do Rio Grande do Norte, apesar da instituição atender alunos dos dois estados vizinhos (Ceará e Paraíba).

De posse das informações sobre o polo em que estão vinculados e o município em que residem foi possível fazer o cálculo da distância em $\mathrm{Km}$ desses dois locais, apresentada na tabela 1. A média da distância foi de $74 \mathrm{Km}$. A EaD, como modalidade de ensino interiorizada, atende alunos de diversas localidades e que não necessariamente vivem próximos aos polos de apoio. Dessa forma, o deslocamento ao polo, para realizar atividades avaliativas ou utilização da estrutura, acarretam custos. Borges (2015) identifica o sistema $\mathrm{UAB}$, e consequentemente os cursos a ele vinculados, como impulsionadores do contato da universidade com as cidades interioranas.

Tabela 1 Distância do município de residência do aluno ao polo que está vinculado

\begin{tabular}{c|c|c}
\hline Polo & Município em que reside & Distância \\
\hline Angicos $/ \mathbf{R N}$ & Assu /RN & $63,6 \mathrm{~km}$ \\
\hline Angicos $/ \mathbf{R N}$ & Santana do Matos $/ \mathrm{RN}$ & $157 \mathrm{~km}$ \\
\hline Angicos $/ \mathbf{R N}$ & Santana do Matos $/ \mathrm{RN}$ & $157 \mathrm{~km}$ \\
\hline Angicos $/ \mathbf{R N}$ & Angicos $/ \mathrm{RN}$ & $0 \mathrm{~km}$ \\
\hline Angicos $/ \mathbf{R N}$ & Angicos $/ \mathrm{RN}$ & $0 \mathrm{~km}$ \\
\hline Angicos $/ \mathbf{R N}$ & Afonso Bezerra $/ \mathrm{RN}$ & $125 \mathrm{~km}$ \\
\hline Angicos $/ \mathbf{R N}$ & Afonso Bezerra $/ \mathrm{RN}$ & $125 \mathrm{~km}$ \\
\hline
\end{tabular}




\begin{tabular}{|c|c|c|}
\hline Polo & Município em que reside & Distância \\
\hline Caraúbas /RN & Rafael Godeiro / RN & $121 \mathrm{~km}$ \\
\hline Caraúbas /RN & Caraúbas /RN & $0 \mathrm{~km}$ \\
\hline Caraúbas /RN & Rafael Godeiro /RN & $121 \mathrm{~km}$ \\
\hline Caraúbas /RN & Janduís / RN & $102 \mathrm{~km}$ \\
\hline Grossos /RN & Mossoró /RN & $45,5 \mathrm{~km}$ \\
\hline Grossos /RN & Grossos /RN & $0 \mathrm{~km}$ \\
\hline Pau dos Ferros /RN & São Miguel /RN & $42,3 \mathrm{~km}$ \\
\hline Pau dos Ferros /RN & Luís Gomes /RN & $52 \mathrm{~km}$ \\
\hline
\end{tabular}

Fonte: Dados da pesquisa (2019).

\subsection{VINCULAÇÃO AO PROGRAMA DE BOLSA PERMANÊNCIA}

As vinculações dos respondentes ao programa de bolsa permanência da universidade pesquisada variaram 2 meses a 1 ano e 1 mês. Sendo que grande parte dos alunos foram beneficiados por cerca de 8 meses a 1 ano. É possível que aqueles que foram vinculados por pouco meses tenham deixado de atender aos requisitos para manutenção da bolsa previstos no Regulamento do Programa Institucional Permanência, visto que, os demais foram desvinculados devido a interrupção do programa.

Quando perguntados sobre as formas em que empregaram o valor da bolsa, constata-se que entre os itens mais presentes estão a despesa com locomoção ao polo, internet domiciliar, despesas domésticas (aluguel, água, luz), aquisição de livros e participação de eventos acadêmicos. Conforme mostra o gráfico 1, seguinte.

Gráfico 1 Itens em que o valor da bolsa foi empregado

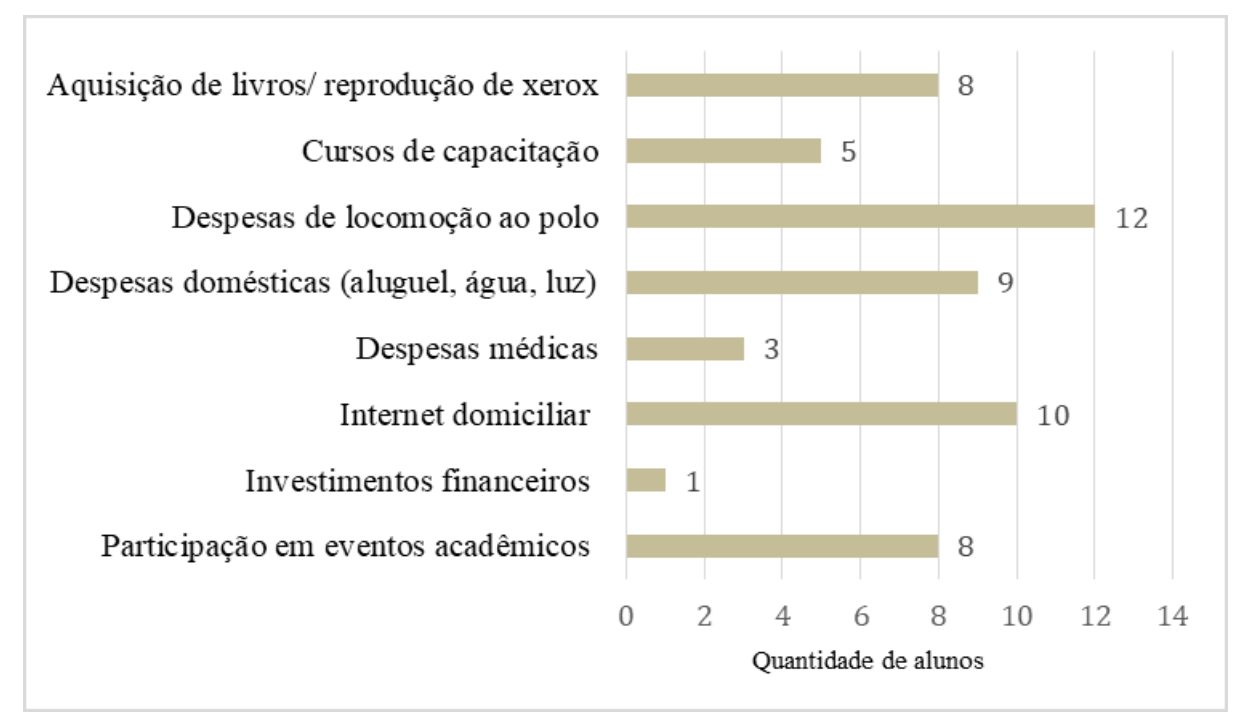

Fonte: Dados da pesquisa (2019). 
Mesmo sendo um curso de modalidade a distância existe a obrigatoriedade de o aluno frequentar o polo para realização de atividades avaliativas, práticas laboratoriais, entre outras atividades acadêmicas. A ida ao polo, considerando as distâncias calculadas no tópico anterior, podem acarretar custos ao aluno, tanto de transporte como de alimentação na instituição. Constatou-se que 12 discentes afirmam ter alocado uma parte ou todo valor do benefício com as despesas de locomoção ao polo. Isto é, quase a totalidade dos sujeitos pesquisados. As despesas com transportes já haviam sido mencionadas como uma das maiores demandas dos discentes na pesquisa da FONAPRACE (2019).

Nota-se, também, que 10 discentes utilizaram o valor para o pagamento da internet domiciliar, item indispensável para o acompanhamento do curso no ambiente virtual de aprendizagem. Alves (2011) e Ferrugini et al. (2013) já mencionaram que é por intermédio das TICs e da internet que é viabilizado o ensino no formato a distância.

Despesas domésticas (aluguel, água, luz) também é representativo, com 9 discentes utilizando a bolsa para esta finalidade. Aquisição de livro/xerox e participação de eventos acadêmicos foram assinalados por oito discentes, estes itens contribuem diretamente no desenvolvimento acadêmico do aluno, conforme já apontado por Alves (2002). Cursos de capacitação, despesas médicas e investimentos financeiros foram os itens em que o valor foi menos empregado.

Houve relatos de que a bolsa permanência contribuiu para aquisição de equipamentos de estudo, tal como notebook. Observa-se que o apoio financeiro possibilita a conquista de outras liberdades que contribuem para o acesso educação. Conforme relato do R8.

Ajudei de certa forma em despesas da casa, distribuindo entre internet, xerox e locomoção aos sábados para realização de trabalhos e provas no campus. E foi com essa bolsa que conseguir comprar o meu notebook para estudos. (Informação escrita - R8, grifo nosso)

De fato, análogo ao expresso por Sen (1999), as privações econômicas acarretam outros tipos de privações que influenciam nas capacidades dos indivíduos alcançarem o que almejam. No caso específico, a privação de renda pode acarretar dificuldades de ida ao polo, dificuldades de acesso ao ambiente virtual de aprendizagem, inacessibilidade a equipamentos de estudo, prejudicando o desempenho e continuidade no curso. 


\subsection{FATORES INFLUENCIADORES DA CONTINUIDADE E DESEMPENHO NO CURSO}

Alguns fatores podem ser facilitadores ou prejudiciais ao processo de aprendizagem. Entre os possíveis influentes da aprendizagem estão as características socioeconômicas, cognitivas e motivacionais do sujeito; além das características do ambiente (ABBAD; BORGES-ANDRADE, 2014).

Com base na pesquisa, 10 discentes elegeram o acesso à internet domiciliar como um fator que muito influencia nos estudos. Conforme já mencionado por Ferrugini et al. (2013), a modalidade de ensino a distância requer a utilização das TICs e internet para sua efetividade. A relevância que os alunos atribuem a internet justifica o fato de que $66,7 \%$ utilizaram o valor da bolsa para este fim.

Outro elemento apontado como bastante influente foi a situação socioeconômica familiar, apontado por oito discentes como algo que intervêm. Este fator já era previsto por autores que consideram a vulnerabilidade socioeconômica como dificultador da democratização do ensino e da educação equânime (COSTA, 2010; SIMIELLI, 2015). Sobre o assunto, vale ressaltar que, com base no estudo de Brocco (2017), os alunos em condição de vulnerabilidade veem a educação como forma de melhoria da vida pessoal e dos familiares.

A disponibilidade de equipamentos pessoais para estudo e a dificuldade de acesso ao polo também se mostraram bastantes influenciadores para continuidade e desempenho dos alunos. A falta destes itens pode representar aspectos de uma inclusão injusta, no qual o aluno acessa a universidade, mas não tem as condições mínimas para permanecer nela (SEN; KLIKSBERG, 2010).

O suporte familiar, considerado por sete alunos com algo que muito influencia, já havia sido observado por Simielli (2015), que lista aspectos relacionados a escolaridade dos pais, nível socioeconômico da comunidade e apoio familiar como de grande relevância para o desempenho escolar.

Também se observou que a facilidade de acesso a eventos acadêmicos e científicos e o acesso a atividades de extensão, pesquisa e ensino são considerados de mediado a muito importantes para os alunos. A importância da participação ativa dos discentes em atividades do tripé universitário foram apontados pelo INEP (2017) e por Sales (2019).

Questionados se a bolsa permanência possibilitou o acesso a outros tipos de atividades complementares, $53,3 \%$, isto é, oito discentes informaram que havia tido acesso a outras 
atividades por intermédio do programa de permanência acadêmica. Entre essas outras atividades estão eventos acadêmicos, projetos de extensão para elaboração de Kits de Física de baixo custo, projeto de teatro da química, projeto de ensino de informática básica, entre outras ações. A seguir comentário do R2 sobre o assunto:

Com o auxílio da bolsa, pude participar de 2 projetos, montagem de kits de laboratório de baixo custo para escolas públicas 2018.1 e 2018.2 e agora participo do projeto círculo de cultura ciência e cidadania 2019.2. logicamente tudo influencia positivamente no crescimento pedagógico e social, molda os andares do discente (Informação escrita - R8, grifo nosso)

Já aquisição de livros e materiais extracurriculares mostrou-se como algo mediado na visão dos alunos. A seguir, no gráfico 2, síntese dos fatores mencionados.

Gráfico 2 Importância dos itens para a permanência e desempenho no curso

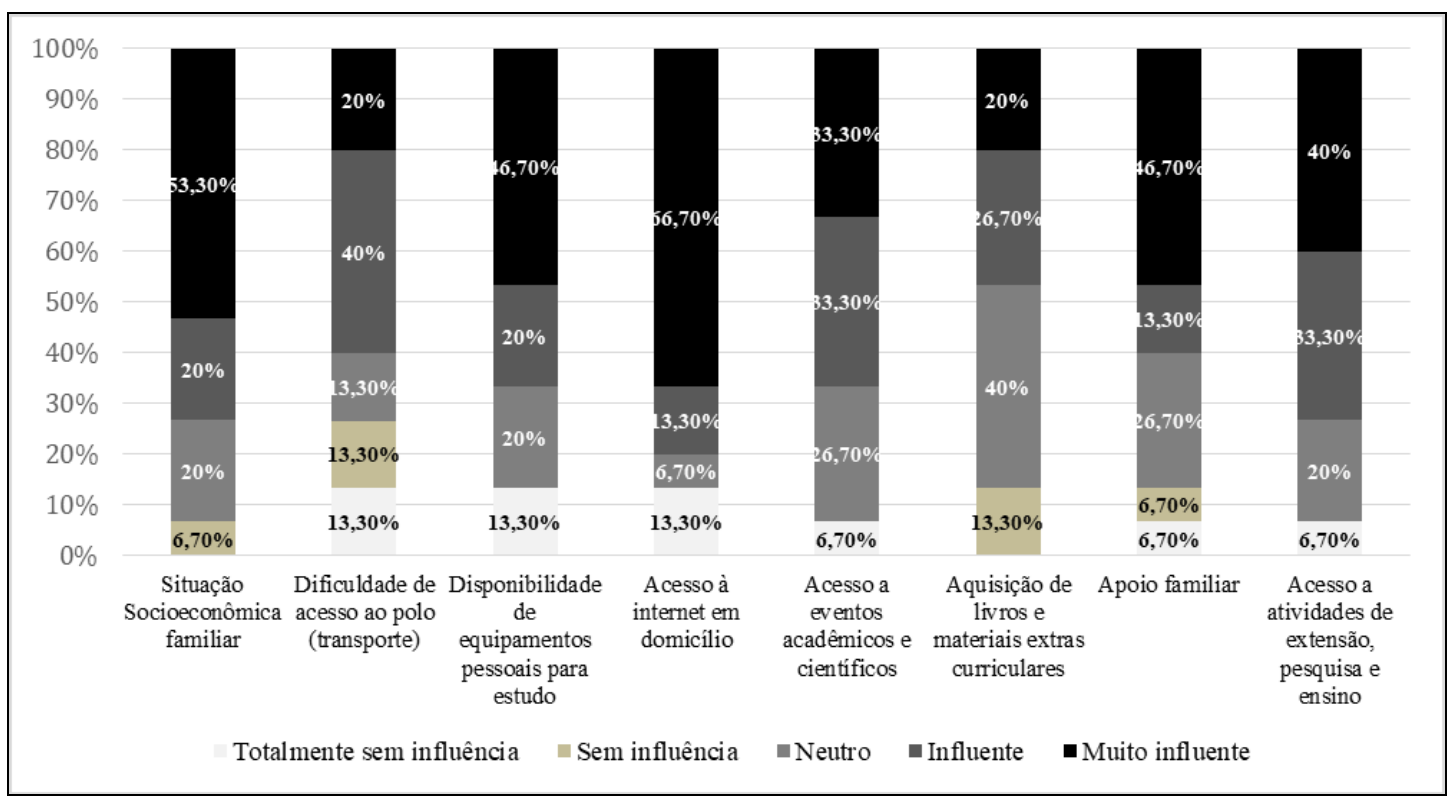

Fonte: Dados da pesquisa (2019).

\subsection{AUTO AVALIAÇÃO ACADÊMICA}

Conforme disposto no Regulamento do Programa Institucional de Permanência da universidade pesquisa, o discente para manter o vínculo com o programa não pode reprovar em mais de duas disciplinas e possuir IRA menor que 5,0. Diante disso, se faz necessário fazer o acompanhamento do rendimento acadêmico dos bolsistas.

Quando questionados como se auto avaliariam com relação ao comprometimento acadêmico antes da implementação da bolsa, 66,7\%, ou seja, 10 discentes se colocaram como 
medianos. Os demais se auto avaliaram como "Nada comprometidos" ou "Pouco comprometidos". Refeita a pergunta, agora questionando sobre o período durante a vinculação com o programa, sete discentes se destacaram como "Muito comprometidos", cinco discentes como "comprometidos" e dois como medianos, não havendo alunos que se auto avaliaram como "Pouco" ou "Nada" comprometidos.

O aumento de desempenho acadêmico por ter sido resultado da maior disponibilidade de materiais para estudo, contato com atividades complementares e maior facilidade de ida ao polo. Como também, pode ser resultante do conhecimento dos parâmetros para desvinculação de bolsas. De acordo com os dados levantados, 10 discentes afirmaram ter conhecimento das normas contidas no Regulamento do Programa Institucional de Permanência da instituição de ensino. Entre estes, oito afirmaram que o conhecimento dos parâmetros influenciou no comprometimento acadêmico, principalmente devido ao receio de perder o auxílio.

\subsection{AVALIAÇÃO DO PROGRAMA DE BOLSA PERMANÊNCIA}

Considerando os pontos destacados como positivos do Programa de Bolsa Permanência da universidade pesquisada, os alunos mencionaram fatores como "Ajuda financeira"; "Comprometimento aos estudos"; "Acesso à projetos"; "Expansão de conhecimentos" e "Desenvolvimento social". Observa-se nos discursos que a bolsa contribui de diversas formas para expansão das liberdades dos alunos, sendo não apenas um auxílio financeiro, mas também, um meio para o progresso em seus estudos e nas relações interpessoais. O relato seguinte do R10 exemplifica essa questão.

Ajuda o aluno a pagar suas despesas e permanecer na universidade. Motiva o aluno a buscar mais conhecimento e a se dedicar mais nas pesquisas acadêmicas (Informação escrita - R10, grifo nosso).

Além de representar uma contribuição para diminuição das limitações de renda nas famílias, visto que, mais da metade contribuiu nas despesas domésticas com o valor da bolsa. Sobre assunto, Alves (2002) já mencionava que a redução das desigualdades socioeconômicas auxiliava na democratização do ensino e da própria sociedade brasileira. E Costa (2010) aponta que o acesso ao ensino superior significa o desenvolvimento da justiça social.

Entre os aspectos negativos listados estão "Poucas vagas disponíveis"; "Duração" e "Valores baixos". O aumento do quantitativo de vagas, duração e valores de bolsas depende de repasses orçamentários e ajustes nos documentos que dispõe sobre o programa. Além do 
aumento no valor e duração da bolsa, também foi sugerido como melhoria do programa a reavaliação dos parâmetros de vinculação, inclusive IRA, e uma maior flexibilização da carga horária para execução das atividades.

O valor da bolsa ainda é baixo diante da nossa vulnerabilidade, precisamos ir ao polo para fazer as atividades, e tem a alimentação de lá também (Informação escrita - R14, grifo nosso).

Com relação as condições de permanecer e concluir o curso sem o apoio do programa de assistência, 10 discentes alegaram não ter condições de permanecer no curso ou que seria extremamente difícil. Os demais informaram que é possível, mas que a bolsa é de grande importância para vida acadêmica e pessoal. O comentário a seguir, do R6, exemplifica o porque a bolsa é importante para continuidade dos alunos.

Não, seria muito difícil. Primeiro que como moro em zona rural aqui o único sinal de internet que chega é via satélite, o que é muito caro (R\$180), segundo a necessidade de deslocamento até o polo de apoio. Ou seja, o corte da bolsa influencia em meu desempenho e permanência no curso. (Informação escrita - R6, grifo nosso).

\section{CONSIDERAÇÕES FINAIS}

O objetivo deste trabalho foi analisar a percepção dos discentes sobre a influência da bolsa permanência para a continuidade e bom desempenho no curso a distância. Com base nos dados obtidos nesta pesquisa, observou-se que, na visão dos discentes a bolsa contribui para continuidade e melhoria do desempenho no curso. E que, consequentemente, a falta do auxílio é capaz de prejudicar a continuidade e rendimento do aluno, visto que o mesmo é utilizado, principalmente, para pagamento de internet e deslocamento ao polo, itens essenciais quando se trata da educação a distância.

Com relação aos fatores que podem oportunizar ou dificultar a permanência e o rendimento dos discentes, foram identificados como muito influentes o acesso à internet, a vulnerabilidade socioeconômica do discente, o pouco acesso à equipamentos pessoais de estudo e as dificuldades de deslocamento até o polo. Fatores que, em geral, foram mencionados como os que receberam maior investimento por parte dos beneficiados.

Nota-se também que a bolsa permanência contribui para a introdução destes alunos em outros tipos de atividades extracurriculares, como eventos e projetos de extensão, sendo, portanto, uma experiência relevante para seu desenvolvimento profissional. Tal contribuição é 
derivada da obrigatoriedade prevista no Decreto $n^{0} 7234 / 2010$ de que os bolsistas devem estar vinculados a alguma atividade do tripé universitário para fazerem jus ao benefício.

Entre as limitações para a execução desta pesquisa está o quantitativo de indivíduos limitado no universo de pesquisa. Recomenda-se para estudos posteriores o comparativo entre os fatores que oportunizam e dificultam a permanência dos alunos da modalidade presencial e a distância. Assim como, de que forma a bolsa permanência é utilizada entre os alunos das duas realidades para superar as dificuldades encontradas no curso.

\section{REFERÊNCIAS BIBLIOGRÁFICAS}

ABBAD, G.; BORGES-ANDRADE, J.E. Aprendizagem humana em organizações de trabalho. In: ZANELLI, J.C; BORGES-ANDRADE, J.E; BASTOS, A.V.B (Org.).

Psicologia, organizações e trabalho no Brasil. Porto Alegre: Artmed, 2014. p. 244-284.

ALVES, J. de M. A assistência estudantil no âmbito da política de educação superior pública. Serviço Social em revista, Londrina, v. 5, n. 1, 2002. Disponível em: < https://www.uel.br/revistas/ssrevista/c v5n1 Jo.htm>. Acesso em: 5 de dez. 2019.

ALVES, L. Educação a distância: conceitos e história no Brasil e no mundo. Revista Brasileira de Aprendizagem Aberta e a Distância, v. 10, 2011. Disponível em: < http://seer.abed.net.br/index.php/RBAAD/article/view/235>. Acesso em: 7 de dez. 2019.

BETZEK, S. B. F. Avaliação do Programa Nacional de Assistência Estudantil: Pnaes na UTFPR, campus Medianeira. Dissertação (Mestrado em Educação) - Faculdade de Filosofia e Ciências, Universidade Estadual Paulista, campus de Marília, Marília, 2015. Disponível em: $<$ https://repositorio.unesp.br/handle/11449/124477>. Acesso em: 5 de dez. 2019.

BORGES, F. A. F. A EaD no Brasil e o Processo de Democratização do Acesso ao Ensino Superior: Diálogos Possíveis. EAD em Foco, v. 5, n. 3, 2015. Disponível em: < https://eademfoco.cecierj.edu.br/index.php/Revista/article/view/283 $>$. Acesso em: 8 de dez. 2019.

BRASIL. Constituição da República Federativa do Brasil. Senado: Brasília, 1988. Disponível em $<$ https://www.senado.leg.br/atividade/const/con1988/con1988 18.02.2016/art 207 .asp $>$. Acesso em 20 set 2019.

BRASIL. Decreto $\mathrm{n}^{\circ} 7.234$, de 19 de julho de 2010. Dispõe sobre institui o Programa Nacional de Assistência Estudantil - PNAES. Diário Oficial da União, Brasília, DF, 20 jul. 2010. Seção 1, p. 7.

BRASIL. INEP. 2015. Instituto Nacional de Estudos e Pesquisas Educacionais Anísio Teixeira. Notas Estatísticas Censo da Educação Superior 2014. Disponível em: 
https://download.inep.gov.br/educacao_superior/censo_superior/documentos/2015/notas sobr e_o_censo_da_educacao_superior_2014.pdf

BRASIL. INEP. 2017. Instituto Nacional de Estudos e Pesquisas Educacionais Anísio Teixeira. Sinopse Estatística da Educação Superior 2016. Brasília: INEP. Disponível em: http://portal.inep.gov.br/sinopses-estatisticas-da-educacao-superior.

BRASIL. Lei nº 13.005, de 25 de junho de 2014. Aprova o Plano Nacional de Educação PNE e dá outras providências. Disponível em http://www.planalto.gov.br/ccivil 03/ Ato2011-2014/2014/Lei/L13005.htm

BRASIL. Portaria n $^{0}$ 389, de 9 de maio de 2013. Cria o Programa de Bolsa Permanência e dá outras providências. Disponível em: http://sisbp.mec.gov.br/docs/Portaria-389 2013.pdf ..

BROCCO, A. K. Aqui em casa a educação é muito bem-vinda: significado do ensino superior para universitários bolsistas. Revista Brasileira de Estudos Pedagógicos, Brasília, v. 98, n. 248, p. 94-109, 2017. Disponível em: < https://www.scielo.br/scielo.php?pid=S2176-

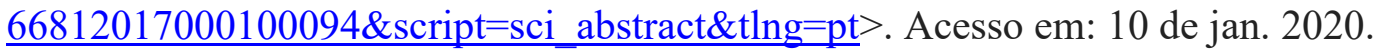

COSTA, S. G. A equidade na educação superior: uma análise das políticas de assistência estudantil. 2010. 202 f. Dissertação (Mestrado em Sociologia) - Universidade Federal do Rio Grande do Sul, Porta Alegre, 2010. Disponível em: < https://www.lume.ufrgs.br/handle/10183/27499> Acesso em: 12 de dez. 2019.

FERRUGINI, L. et al. Educação a distância como política de inclusão: um estudo exploratório nos polos do Sistema Universidade Aberta do Brasil em Minas Gerais. Revista Gestão Universitária na América Latina-GUAL, v. 6, n. 2, p. 1-21, 2013. Disponível em: < https://periodicos.ufsc.br/index.php/gual/article/view/1983-4535.2013v6n2p1> Acesso em: 8 de dez. 2019.

FONAPRACE. V Pesquisa Nacional do Perfil Socioeconômico e Cultural dos (as) Graduandos (as) das IFES. Relatório Executivo. 2019. Disponível em: http://www.fonaprace.andifes.org.br/site/index.php/documentos/perfil-socioeconomico/. Acesso em: 2 de dez. 2019.

GUIMARÃES, S. M. M. Permanência discente: gestão da EaD no instituto federal do norte de minas gerais: estudo de caso. 2017. 230 f. Dissertação (Mestrado) - Curso de PósGraduação em Gestão Pública, Universidade de Brasília, Brasília, 2017. Disponível em: < https://repositorio.unb.br/handle/10482/23526>. Acesso em: 10 de dez. 2019.

LOBO, R. L.; MOTEJUNAS, P.R.; HIPÓLITO, O. e LOBO, M.B. A Evasão no Ensino Superior Brasileiro. Cadernos de Pesquisa, Fundação Carlos Chagas, V-37, N-132. set/dez 2007. Disponível em: < https://www.scielo.br/pdf/cp/v37n132/a0737132>. Acesso em: 20 de dez.2019.

NEVES, C. E. B; RAIZER, L.; FACHINETTO, R. F. Acesso, expansão e equidade na educação superior: novos desafios para a política educacional brasileira. Sociologias. Porto Alegre. Vol. 9, n. 17 (jan./jun. 2007), p. 124-157, 2007. Disponível em: < 
https://www.scielo.br/scielo.php?pid=S151745222007000100006\&script=sci abstract\&tlng=pt $>$. Acesso em: 3 de dez. 2019.

SALES, A. C. M. Cotas no ensino superior: a trajetória acadêmica do aluno cotista na UFRN. 2019. 143 f. Dissertação (Mestrado) - Curso de Programa de Pós graduação em Psicologia, Universidade Federal do Rio Grande do Norte, Natal, 2019. Disponível em: < https://repositorio.ufrn.br/jspui/handle/123456789/27963 > Acesso em: 10 de jan. 2020.

SEN, A. Desenvolvimento como liberdade. Editora Companhia das Letras, 1999.

SEN, A.; KLIKSBERG, B. As pessoas em primeiro lugar: a ética do desenvolvimento e os problemas do mundo globalizado. Editora Companhia das Letras, 2001.

SIMIELLI, L. E. R. Equidade educacional no Brasil: análise das oportunidades educacionais em 2001 e 2011. 2015. 134 f. Tese (Doutorado) - Curso de Administração Pública e Governo, Fundação Getúlio Vargas, São Paulo, 2015. Disponível em: < http://bibliotecadigital.fgv.br/dspace/handle/10438/2204/browse?value=Equidade+educaciona $1+$ no + Brasi $1 \% 3 \mathrm{~A}+$ an $\% \mathrm{C} 3 \%$ A 1 lise + das + oportunidades + educacionais + em $+2001+\mathrm{e}+2011 \&$ typ e=title $>$. Acesso em: 15 de dez. 2019.

YIN, R. K. Pesquisa qualitativa do início ao fim. Penso Editora, 2016. 